\title{
Murdochian Presentationalism, Autonomy, and the Ideal Lovers' Pledge
}

\author{
T. Raja Rosenhagen \\ Ashoka University, raja.rosenhagen@ashoka.edu.in \\ ORCID: 0000-0002-1348-5196, https://orcid.org/0000-0002-1348-5196
}

\begin{abstract}
How to conceptualize loving relationships so as to accommodate that just love is geared toward preserving and fostering individual autonomy? To develop an answer, this paper draws on the recent debate on the rational role of experience to motivate a view dubbed Murdochian presentationalism. Murdochian presentationalism takes seriously two presentationalist ideas: 1) individuals harboring different world views who respond to identical situations differently can be equally rational; 2) our views and concepts develop under the constant pressure of experience. It combines these ideas with Murdoch's tenet that coming to know others (and thus being able to do well by them) requires unselfish love, construed as just attention that involves a continuous refinement of our evaluative concepts and makes us better attuned to what is real. Complemented with a broadly Kantian notion of autonomy, the resulting view fits the bill. The paper ends on a sketch of what is dubbed the ideal lovers' pledge and a comment on what metaphor the view arrived at suggests for thinking about loving relationships.
\end{abstract}

Keywords: just love, autonomy, just attention, Iris Murdoch, presentationalism, love as harmony

\section{Introduction}

When lovers forge loving unions, union theorists think, their identities merge into a we-identity. Henceforth, the lovers' future decisions depend no longer on their individual outlooks, but on the fused outlook they are taken to share. In a merger, one may suspect, individual autonomy is diminished or lost. ${ }^{1}$ But shouldn't just love preserve and foster individual autonomy? In the context of her rejection of the so-called love-justice dichotomy, Rachel Fedock considers something quite like this line of thought (cf. Fedock 2020). Here is a gloss:

P1: Love, on union theories, diminishes individual autonomy.

P2: To be just, love must preserve or foster, not diminish individual autonomy.

$\mathrm{C}:$ On union theories, love is unjust.

Union theorists may accept P2, yet insist that maintaining loving unions is a practical task, one that lovers can execute justly (cf. Kühler 2011). Call this Kübler's contention. If it is right, if C ought thus to be resisted, and provided that the above argument is valid, P1 must be wrong. Some hold that it is. Consider, for example, the following passage by Neil Delaney:

(1) It's not as if your wishes for consolidation and identification on the one hand, which are after all simply aspects of the profound psychological merging sought after in romance, and the desire to preserve the integrity of your personal boundaries on the other, are hopelessly irreconcil[i]able [sic!] aims. (Delaney 1996, 341)

1 See Kühler 2020, section 3, for a fuller overview, references, and a useful classification of union views. 
Delaney, too, accepts the union theorists' basic idea and talks about love in terms of psychological merging. That romantic lovers want to form a distinctive form of we with their beloved, he grants, is “pretty generally accepted" (ibid., 40). In the paper cited, he does not use the word 'autonomy.' Yet arguably, his reference to the desire to preserve the integrity of one's personal boundaries points to exactly that: a desire for the preservation of one's individual autonomy. So construed, Delaney denies, in (1), that the romantic lovers' desire to psychologically merge and the desire for the preservation of individual autonomy are hopelessly irreconcilable. Love, he thinks, construed (with union theorists) as a kind of merger, and the preservation of individual autonomy are compatible. ${ }^{2}$ Delaney, thus, denies P1.

I agree with Fedock: there is no dichotomy between love and justice. I also sympathize with Kübler's contention: maintaining loving unions, is a practical task that can be executed justly. Delaney is right, too: no principled tension links love and the preservation of autonomy. But if Delaney is right and P1 false, we should set our argument aside. Resting on a false premise, it doesn't establish its conclusion.

Note that in setting the argument aside I don't wish to save union theories. My qualms about them will transpire near the end of this paper, but are anyway mostly tangential to this paper. P2 of the above argument, however, is independently interesting. The normative ideal to which it points has implications that go beyond what I have so far attributed to any of my interlocutors. If we take 'just love' to be a non-empty term, P2 will entail a general version of Kübler's contention, viz. that (maintaining) love (is a task that) can be (executed) just(ly). On this view, at least in its more ideal forms, love does not just form no dichotomy with, but au contraire conforms with justice. But endorsing P2 involves more than accepting this. As we saw, Delaney, too, takes love and the preservation of autonomy to be reconcilable. P2 goes further, as it suggests that there is a positive link between just love and individual autonomy: love that is just-and ipso facto aligned with virtue-is protective and supportive of individual autonomy. With this interpretation on the table we can ask: why is just love a matter of preserving and fostering individual autonomy? Against the backdrop of what notion of just love and on what conception of individual autonomy is $\mathrm{P} 2$ a good claim to make?

In what follows, I work toward providing answers to these questions. In part, I do this by drawing on and developing aspects of Iris Murdoch's work, which I in turn motivate by taking my cues from the debate on experience's rational role. Before I begin, allow me some preliminary remarks. First, Murdoch, following Simone Weil, characterizes love as a quality of attention. ${ }^{3}$ Love, she takes it, ideally involves what she calls just attention. Paying just attention to another is a way of doing justice to them and their perspective as one looks at them and actively imagines what they are like and what may underlie and make intelligible their actions. ${ }^{4}$ Such looking is undistorted by selfish desires or fears about how others should or might be (or act) to serve or threaten one's ego and its selfish ends.

2 Note that Delaney characterizes the merging involved in romantic unions as psychological. He also emphasizes that people want their love to generate and sustain a commitment to them of a certain type (cf. Delaney 1997, 40). While I wish to remain neutral with respect to the former, I fully agree with the latter. Later, I will have more to say about what I take such a commitment ideally to involve.

3 For a very helpful discussion of Weil and Murdoch, see Broackes 2012, esp. 19ff., and Broackes 2019.

4 Murdoch on the importance of imagination: "The formulation of beliefs about other people often proceeds and must proceed imaginatively and under a direct pressure of will. We have to attend to people, we may have to have faith in them, and here justice and realism may demand the inhibition of certain pictures, the promotion of others. [...] To be a human being is to know more than one can prove [...]" (Murdoch 1998, 199). Importantly, then, as we interact with others, we take them to be some specific way and to act out of some motives (not others), go beyond the facts, may exhibit faith in them, succeed or fail to do them justice and, thus, be more or less attuned to reality. 
Refraining, for now, from further examining the specifics of the notion of just attention, let us place the following on record: as for Fedock, for Murdoch, too, the idea of a fundamental dichotomy between love and justice must be misguided. Surely, a lover's love may be selfish, misguided, misdirected, and tainted in various ways. "Love is the general name of the quality of attachment," Murdoch says, "and it is capable of infinite degradation and is the source of our greatest errors." 5 And yes, some of the mistakes we commit in the name of love will be errors of injustice. Yet if the conflict between love and justice is taken as fundamental, then for Murdoch, such a proposal must rest on mistaking love's degraded varieties as exhausting what love is, i.e. on a failure to comprehend what love is ideally.

Second, the Murdochian account that I will develop, while friendly toward Kübler's contention, also points beyond it. With Murdoch, I take it that loving is at least also a matter of attending to our beloved justly. We attend to others and their surroundings continually-indeed near-continuouslyand such attention co-determines what we see and how we subsequently act. Arguably, attention is at least to some extent responsive to the will—we can partly control, modify and adjust it. That we can willingly snap out of a particular way of attending to things is familiar enough. Just think of a situation in which you catch yourself casting things in a light that is too pessimistic-under the influence perhaps of being frustrated about something quite unrelated. If you realize that your brooding colors your overall perception of the situation, you may readjust and look again. Similarly, the way we attend to a beloved is something we do and at least partly control. Emphasizing that attention responds to the will may thus tempt us to construe maintaining love as involving a (near-)continuous practical activity-attending to one's beloved — which yields subsequent actions that accord with and respond to what we see (or imagine). Just love, we may then think, is a practical ideal governing this activity. Though this seems apt, for Murdoch-as will transpire-just attention is a theoretical task, too; it requires getting one's moral concepts right and deploying and developing them on subsequent occasions of attention to increase our freedom from selfish fantasy, in ways geared toward what is good and real. Maintaining love justly, so construed, is both: a practical and a theoretical achievement.

Recall, third, that I am interested in a conception that sustains P2, i.e. one on which just and ideal lovers, qua just lovers, recognize and foster their beloved's individual autonomy (in a sense to be spelled out). Following Murdoch's lead, I propose that excelling at the latter requires the lover's continuous acknowledgment of and response to the fact that their respective beloved, qua individual, differs from them. But if this is accepted, the initial portrayal of the union view begins to look skewed. For if just love requires the acknowledgment of and response to the fact that our beloved differs from us, then in love so construed, our identities cannot and do not merge. If asked to provide an image of ideal romantic lovers, respondents typically provide a description of a couple that has formed some sort of deep physical or psychological union, ${ }^{6}$ a union in which some common goals may be found

5 The passage continues, "when it is even partially refined it [i.e. love] is the energy and passion of the soul in its search for Good, the force that joins us to Good and joins us to the world through Good." Murdoch 1970, 103. That Murdoch's notion of love borrows from the Platonic eros is obvious. For an exploration of this topic see Hopwood 2017. In Rosenhagen 2019a, I suggest that laying her notion of love alongside Aristotle's philia is instructive as well.

6 I take no stance on whether romantic love is essentially physical, with respect neither to a) what kind of relation it is, nor b) what occasions it. As for a), like Jollimore, I hesitate to assert or endorse necessity claims regarding romantic love (see Jollimore 2019, 67). As for b), the question what occasions love is causal and though reasons may be causes, not all causes for love need to be reasons. In discussions about love, this point is sometimes missed. Hurka 2017 thinks that reasons for romantic love are both normative and non-normative. Engels Kroeker 2019, like Martin 2015, holds that one's reasons for love may be just a-rational, just rational, or hybrid. Though I am sympathetic to the latter, I take issue with talk of a-rational reasons. I prefer to say that in forming bonds of romantic love, some of the properties lovers possess or attribute to one another are causes for love. These may, but need not also serve as reasons. 
and jointly pursued, while others will (and indeed should) be pursued individually, but with the support from one's beloved. With a few minor caveats, something quite like this is surely acceptable. ${ }^{7}$ Also, to say this is not to make a bold metaphysical claim. There is a completely innocuous sense in which such unions do exist—derivatively and metaphysically grounded in the existence of the individuals forming it and e.g. their attitudes and commitments toward each other. ${ }^{8}$ To characterize the notion of loving relationships, I suggest, it is worth exploring what attitudes and commitments they might ideally involve and how these may sustain the claim that such relationships preserve and foster autonomy. I do this by looking at the Murdochian equation of love with just attention and by developing the conception of a mutual commitment that I will dub the ideal lovers' pledge.

On this note, a caveat: love, even just the romantic sort, comes in many varieties. 'The ideal lovers' pledge' labels a commitment that, I believe, should appeal to those who like me endorse P2. But the label's determinate article is not meant to convey that the ideal it picks out is universal (or prescriptive). It need not pick out the only way in which a commitment people make toward each other qua lovers may be ideal as there may just not be only one such way. And yet I trust that a large variety of romantic relationships can be understood as aiming toward something much like what it picks out.

In sections II and III, I sketch a view I dub Murdochian presentationalism. To motivate it, I look, in section II, at a debate within contemporary philosophy of mind and epistemology and show how presentationalism escapes difficult problems that beset its more prominent contenders. Doing this, I think, pays off. ${ }^{9}$ For I believe that presentationalism provides an interesting model of empirical reasoning which can be fruitfully extended to specifically moral reasoning (see Rosenhagen ms.). Presentationalism and Murdoch's account of love, I think, are a natural fit. In section III, I thus use presentationalism to motivate certain crucial aspects of Murdoch's view, show how conversely, the latter supports the former, and blend the two by giving presentationalism a Murdochian twist. In section IV, I outline the Murdochian (presentationalist's) notion of freedom and add to the mix a broadly Kantian notion of individual autonomy. With this in hand, I show, in section V, how the view thus arrived at sustains P2 and close by presenting the ideal lovers' pledge and by drawing attention to the kind of metaphor Murdochian presentationalism suggests for thinking about loving relationships more generally.

\section{Motivating Presentationalism}

As my approach is informed by recent debates on the rational role of experience, this section supplies the requisite background. If asked how to conceptualize perceptual experience, most philosophers affiliate with either of two camps - representationalism or relationalism. Presentationalism, my preferred view, belongs to neither. To introduce it, I will sketch the two alternative views and then show how presentationalism differs from them and escapes some pressing problems they face.

7 One caveat: couples provide just the simplest and most common kind of case. We need not embrace the (false) claim that relationships of romantic love are confined to couples, nor the prescription that they should be.

8 I adopt the notion of grounding and the permissive metaphysical stance implied here from Schaffer 2009.

9 According to Sellars, the "aim of philosophy, abstractly formulated, is to understand how things in the broadest possible sense of the term hang together in the broadest possible sense of the term" (Sellars 1963, 1). Below, I suggest that practical and theoretical pursuits hang together more tightly than standard disciplinary divisions would suggest. 


\section{II.1 Representationalism}

The number of representationalist accounts is legion. As the label indicates, their characteristic tenet is that experience is fundamentally a matter of representation; like thought and belief, it has representational content. ${ }^{10}$ Representationalists disagree on various issues. One set of issues concerns what content is, another how it relates to the so-called phenomenal character of experience - often glossed as what it's like to have an experience. Bracketing these, let us note that the content claim invites a temptingly simple account of the rational role of experience, along with a general story of how experience can play it. On it, if things go well and are as they seem, experiential content supplies experiential premises. These enable experience to play its rational role: justifying beliefs. ${ }^{11}$

Representationalism faces serious problems. Here is one: representationalism about experience naturally combines with foundationalism, according to which experiential content serves as a regress stopper at which the demand for justification comes to an end. ${ }^{12} \mathrm{It}$ is, however, far from clear in virtue of what experiential (or better: perceptual) ${ }^{13}$ content is to have such impressive justificatory powers.

Second, suppose that at least sometimes, perceptual content provides grounds for justification. For these to be fertile, the subject's conceptual apparatus would need to be such as to enable her to properly exploit that resource. If the subject's beliefs are wrong or irrational, or her conceptual apparatus muddled, ${ }^{14}$ so may be the inferences she draws from her experiential content - even if the latter possesses unabated justificatory power. Representationalists leaning toward foundationalism who believe that experiences (must) ${ }^{15}$ provide potential grounds for justification must therefore also provide this: an account of what a subject's view and concepts must be like for the subject to be able to exploit the goods that perceptual experience is said to deliver - at least in the good case.

Note, third, that these challenges become harder if experiential content can be determined, at least partially, by not just the external mind-independent items it purports to represent, but also the subject's beliefs, conceptional capacities, or other internal factors. One way to think of such subject-born determination is in terms of muddled concepts affecting experiential content, another in terms of topdown effects on experience from background states, e.g. beliefs, hopes, expectations, desires, fears, biases, even moods. Perhaps experiential content is often affected by either muddled concepts or background states. Plausibly, such effects are often outside the subject's ken. This creates trouble. For if experiential content may be so affected, why and when are we to rely on it for justification? ${ }^{16}$

10 I henceforth drop the qualifier 'representational.'

11 Representationalists favoring different notions of content will vary in how they fill in the story. For this paper, the specifics don't matter - I just need to provide a generic version.

12 It is notoriously difficult for coherentists to accommodate the foundationalist intuition that experiential contents or the beliefs associated with them carry special justificatory weight.

13 Typically, "perceptual experience" is used as the broader term and 'perceive' is used factively. On this usage, one can have a perceptual experience as of $p$ even if $p$ is not the case, but cannot perceive that $p$ unless $p$ is the case.

14 It cannot be completely muddled. The idea of a concept with respect to which every belief we could possible hold is false is the (absurd) idea of a concept that lacks determinate content (Rosenhagen 2019b).

15 Any epistemology worth its name, McDowell insists, must accommodate receptive knowledge lest it make empirical rationality unintelligible (cf. McDowell 2009, 468, citing Rödl 2007, ch. 3 for support). Rejecting foundationalist pictures according to which "the knowledge experience makes available to us constitutes the foundation of all our discursive activities", he claims that the subject's ability to know through perception "is intelligibly only as an element in an ongoing condition of being rationally at home in the world - so only in a context in which our discursive activities are already under way" (McDowell 2019, 394, emphasis added). My point is that McDowell must put flesh on the bones of what he gestures at when he helps himself to the expression "being rationally at home in the world."

16 Are such effects pervasive? Some philosophers (e.g. Siegel), and cognitive neuroscientists affirm this (e.g. Hohwy 2014), many entertain it at least as possible and thus potentially worrisome. For dissent, see Firestone \& Scholl 2016. 
Representationalists, then, must answer at least three queries: if (as is natural) they endorse foundationalism, how does experience get its justificatory power? What must a subject's view and concepts be like to allow them to harness such power? How to rule out that one's experience is codetermined by muddled concepts or background states in such a way that experience is robbed of its justificatory power? Without answers to these questions, representationalists must fear that experience may often fail to execute its alleged rational role, or execute it poorly. ${ }^{17}$

\section{II.2 Relationalism}

Relationalism, or naïve realism, is explicitly opposed to representationalism, since as per one of its three main tenets, experience lacks content. ${ }^{18}$ Second, experience is taken to be fundamentally a relation, often called acquaintance, between subjects and mind-independent worldly items ${ }^{19}$ that obtains in further specifiable circumstances (e.g. lighting conditions, the subject's visual acuity, physical location vis-à-vis the items, distribution of attention, etc.). Typically, the third is this: acquaintance with worldly items constitutes experiential phenomenal character, the what it's like to undergo it. Experience, relationalists think, plays two main roles. For one, it presents mind-independent objects to subjects, thus making them available for reference and demonstrative thought. ${ }^{20}$ The second role, again, is that of serving to justify perceptual beliefs. Like representationalists, relationalists face some well-known problems. I just mention a few: first, relationalists have a hard time providing a positive account of some illusions and hallucinations - especially if in them, the individual is not related to suitable mindindependent items. Second, their notion of acquaintance is notoriously difficult to characterize. Third, it is hard to explain how content-less experience can justify beliefs. ${ }^{21}$ Fourth, if relationalists take the subjective dimension of experience to be exhausted by its phenomenal character and if they take it to be constituted by what worldly items experience relates its subject to, it seems they must rule out direct effects of background states on experience as impossible. ${ }^{22}$

Relationalism is still in the making, but these issues must be addressed. ${ }^{23}$ Here is one more, familiar from above: experiences must hook up with concepts and beliefs somehow. And if the

17 Representationalists could accommodate such effects by holding that experience has a rational standing that is modifiable by background states (cf. Siegel 2017). In Rosenhagen 2018, I argue that this is unsatisfactory. It yields a highly revisionary view of experience, leaves it unclear how representational content and the phenomenology of experience relate, leaves what is rational for subjects to do, upon having a certain experience, opaque to them, and fails to capture the important rational role experience plays both in individual reasoning and in empirical debate.

18 Some maintain that one should retain and combine relationalist and representationalist insights. Examples are Schellenberg $(2014 ;$ 2018) and McDowell (2013). However, to the extent that these philosophers also hold that experience does have content, staunch relationalists cannot agree with them (see Nanay 2014).

19 Depending on individual relationalists' ontological proclivities, the mind-independent worldly items are variously construed as objects, as properties, or as facts (i.e. sets of objects and properties). Examples are Brewer 2011, 2018, and 2019a and 2019b (objects), Genone 2014 and 2016 (appearance properties), and Fish 2009 (facts). I discuss various challenges that I take these views to face at length in Rosenhagen 2018.

20 As Campbell puts it, experience brings the environing items and their qualitative features, "into the subjective life of the perceiver" (Campbell \& Cassam 2014, 33).

21 These problems relate to an issue Jonathan Kvanvig identifies as 'Sellars' problem'. According to it, it is hard to see how experience that lacks propositional - or, for that matter, any - content could serve to justify beliefs, but also hard to see how, on the view that experiences do have content, one is to determine which ones can generate justification (cf. Kvanvig 2007, 169-70). As we saw above, representationalists face the latter kind of issue, whereas the former issue poses a challenge to relationalists.

22 The word 'directly' indicates that such effects are not mediated via attention. Genone 2016, too, notes the problem.

23 To address some of the challenges listed, people have begun to develop relationalist positions that jointly form what is now sometimes dubbed New Wave Relationalism. Some of those who are busy developing interesting new versions 
subject's concepts are muddled, so may be the way their experiences, concepts, and beliefs hook up. If so, the already difficult problem as to how experience can play its rational role gets even harder.

In the next subsection, I sketch a conception of experience and its rational role developed and defended by Anil Gupta: Reformed Empiricism, or presentationalism. As will transpire, presentationalism dodges many of the problems discussed as it offers a more general conception of the rational role of experience, one experience can play come what may. This makes it an independently attractive view. It is more appealing even, I think, once we realize that it combines well with and in fact serves to motivate the view Iris Murdoch defends with respect to how we may improve the evaluative practices characteristically involved in our morally relevant interactions with others, including those we love.

\section{II.3 Presentationalism}

In experience, presentationalists hold, items presented to consciousness manifest appearances. 'Appearances', as they use the term, denotes the experience's subjective aspect - what experiences of items are if considered from the subject's point of view. What manifests them can be environing mindindependent items, yet they may also result from other factors, e.g. environmental conditions and subjective features, including the subject's constitution, her mental states, even brain states. But appearances, presentationalists insist, are multiply factorizable (see Gupta 2006, ch. 1): there are various ways the world and the experiencing subjects could be, each of which would jointly manifest appearances that from the subject's viewpoint are identical. Different factors, that is, can generate subjectively identical appearances. Accordingly, appearances, considered in isolation, don't reveal what they are of. Pace representationalism, they thus don't have, qua experience, any representational content, so that experience alone does not provide subjects with anything to endorse or reject (though content may be associated with it). ${ }^{24}$ Experience by itself thus cannot serve to justify anything. Instead, presentationalists hold, the rational role of experience is this: having an experience makes rational certain transitions - transitions, inter alia, to perceptual judgments. Which transitions to which judgments? This crucially depends on what background view one inhabits. ${ }^{25}$ Different views, if combined with the same experience, may make rational different transitions. How? Roughly, thus: views contain beliefs, yet also, crucially, linkages that rationally link each possible experience with view-specific transitions to e.g. perceptual judgments that it would be rational to transition to were that experience had. ${ }^{26}$ Accordingly, whenever some appearance manifests in a subject's consciousness, then in light of her view, some transitions to (inter alia) perceptual judgments become rational.

To illustrate, consider Pia. Pia, suppose, is unfamiliar with the Müller-Lyer illusion. Upon seeing it, certain appearances manifest in her consciousness. As Pia has no reason to suspect funny business, having this experience, in light of her view, makes it rational for her to transition to the following judgment: "These two lines differ in length." ${ }^{27}$ Contrast Mia, Pia's twin. Unlike Pia, Mia is familiar

of relationalism are Ori Beck, Craig French, Heather Logue, Farid Masrour, Ian Philips, Umrao Sethi, and my colleague Kranti Saran.

24 Gupta eschews the idea that experience has content as otiose, but that move is optional (cf. Gupta 2019, 243, fn. 31; also Rosenhagen 2018, ch. 10).

25 Henceforth, I drop the qualifier 'background' and just talk about views.

26 Views may also contain linkages to other activities, such as referential activities or ostensive definitions (see Gupta 2019) or to suspension of judgment. Indeed, I think presentationalists can broaden this idea and allow that a view can also contain linkages to all sorts of actions (cf. Rosenhagen ms.).

27 One may wish to insist that there must be an absolute sense in which one cannot be fully rational if upon having a certain experience, against the backdrop of a certain view, one transitions to a perceptual judgment that is false or 
with the illusion. But it is robust; knowing it neither undoes it nor does it alter its appearance. Indeed, we may suppose that Mia is being appeared to exactly like Pia. However, conjoined with Mia's view, having an experience involving that exact same appearance makes it rational for Mia to transition to a different judgment - to wit: "These two lines are the same length."

Presentationalists dodge issues that beset representationalism and relationalism. They have no need for the notion of acquaintance, nor do they insist that the phenomenology of experience, i.e. the set of the appearances it comprises, is constituted by mind-independent items. On Gupta's presentationalism, experience lacks content, and what does not exist cannot be distorted by background states. Such states could also affect appearances, though. ${ }^{28}$ But crucially, even if they did, the rational role of experience as presentationalists construe it would remain completely unhampered. For any experience $e$, having $e$ against the backdrop of any view will make some transitions to e.g. judgments rational-regardless of how $e$ is generated, whether it is an illusion, hallucination, or neither.

Note also that if experience lacks content, one cannot assign it an inappropriate justificatory weight. ${ }^{29}$ Of course, on presentationalism, too, things can go wrong in familiar ways. Note two: first, upon having an experience $e$, we can fail to transition to anything that it would, upon having $e$ and in light of our view, be rational to transition to. Second, we might, upon having $e$, rationally transition to perceptual judgments that are ill-justified, false, even irrational. In the first kind of case, we behave irrationally conditional on our view. Surely, this is possible and may even happen frequently. In the second kind of case, we are also rationally off-target, but differently. For if our view is such that against the backdrop of it, upon having $e$, we rationally transition to judgments that are false, ill-justified, or irrational, then our view must at least in part be false, ill-justified, or irrational as well. Nevertheless, relative to that view, the transitions to the judgments we make, upon having $e$, may be perfectly rational.

Scientific theories should be falsifiable and scientists be able to specify experiences that are incompatible with their pet theory. ${ }^{30}$ Analogously, views should contain linkages from possible experiences to judgments that are at odds with it. Judgments one transitions to rationally, upon having such experiences, will create rational pressure to suspend judgment, or revise one's view (along with the beliefs and concepts it contains). Such revisions may lead to improved views - less irrational, more justified, and more knowledgeable. But if we revise our view in the wrong direction (perhaps rationally so), it may get worse. Future experience, the idea goes, will tell. Importantly: even if our views are partly false, ill-justified, or irrational, and our conceptual apparatus partly muddled, the rational role of experience will not be undermined. ${ }^{31}$ For against the backdrop of any view, even muddled ones, having experiences will make it rational to engage in some transitions (and not others). ${ }^{32}$ Accordingly, the rational role of experience is completely general. Provided that experience is

even irrational. This point can be granted. However, one can be irrational in this absolute sense while at the same time being completely rational in another: how one transitions from a partly incomplete, false, or even irrational view, if confronted with a given experience, to perceptual judgments can be perfectly rational, conditional on the view.

28 Non-Gauptik versions of presentationalism may keep a notion of content, which could then be co-determined by background states.

29 On versions of presentationalism on which an experience is associated with some content, the specifics of such association are view-dependent, too. On them, too, experience in and of itself cannot be assigned justificatory weight.

30 If there were none, the theory would be useless for explanatory and predictive purposes and lack empirical content.

31 Again, there are limits to how muddled views can be. There must also be limits to how irrational something can be and still count as a view that contains determinate rational linkages between experiences and perceptual judgments. Details concerning such issues become interesting quickly, but also more complicated than presently useful.

32 Views can be poor and rational transitions can lead to uninteresting judgments, e.g. "I (seem to) see something blue." 
combined with a view, experience cannot fail to play it. ${ }^{33}$ And as long as our view contains linkages such that having certain experiences would make rational transitions to judgments that are at odds with it, our experience can provide the friction and pressure required for us to be rationally compelled to change, perhaps improve our views in response to them. ${ }^{34}$ Ideally, things go well and eventually, possibly after many detours, we may get things right.

This completes my sketch of presentationalism. I have argued that presentationalism escapes a number of serious problems that beset its most prominent contenders. For this reason alone it is worth pursuing. As we will see, presentationalism is also appealing as a way of thinking about moral reasoning, especially the Murdochian kind. Let us move on, then, and add to it a Murdochian twist.

\section{III.Murdochian Presentationalism}

Iris Murdoch's central tenet is that in morality, love is a central notion (see e.g. Murdoch 1970, 2, 30, 46). According to her, moral progress and acting well-i.e. in ways that are attuned to what is real, aim at what is truly good, and truly benefits others-require love, construed as just attention. "Love," she famously says, "is the perception of individuals, [...] the extremely difficult realisation that something other than oneself is real" (Murdoch 1959, 51). Love requires that we avert our attention away from the self - that "dazzling object that [is such that] if one looks there one may see nothing else" (Murdoch 1970, 31) - and direct it at others. Truly seeing them, not caricatures that serve the enemy of moral life: the fat relentless ego (ibid., 52), requires attending to them unselfishly, looking at and imagining them (and their actions) in ways that do justice to who they are.

To illustrate, consider selfish Sid. To Sid, others matter only as they further or impede the pursuit of his goals. How he characterizes others reflects his selfish needs: useful, influential, yet exploitable, weak, threateningly smart, or worthlessly stupid, say. In characterizing others, we must use some labels. Yet Sid's coarse categorization transforms the people he interacts with into shallow and distorted caricatures of who they are. To him, they appear as shadows cast by the dim light of his needs, not as the complex characters they are, driven by individual motives, desires, and ideas, and as who they might be revealed through the loving gaze of just attention. For our characterizations of others and their actions to become better attuned to what is real and particular, Murdoch urges, and for our moral concepts to improve through subsequent occasions of judicious application, we must look and imagine. But Sid, being the sorry selfish lad we imagine him to be, has little intrinsic motivation to attend to who others really are or to imagine how their own actions may look to them. To him, doing this seems like a terrible waste of time. Forfeiting opportunities to attend and improve, his concepts remain coarse and blunt instruments. They cover up rather than reveal, deform the people he meets rather than help him appreciate the subtle shape of their characters - his vision remains distorted, distracted, and unrefined.

Let us blend Murdochian language with that of presentationalism: first, selfish attention to others may distort how they appear to us and may determine what evaluative assessments of them we are rational to transition to as we evaluatively characterize them and their actions. Second, our experience of others, if combined with a view that is selfish as it contains selfish beliefs, may make it rational for

33 Presentationalism is compatible both with the relationalist claim that experience serves to bring subjects in touch with mind-independent items and with a claim both representationalists and relationalists endorse: experience may help justify beliefs. But neither claim, presentationalists will insist, properly captures experience's fundamental rational role.

34 Like Popper rejected unfalsifiable theories as metaphysical (meant pejoratively, see e.g. Churchland 1975), a view $v$ on which any possible experience makes rational transitions to judgments in line with $v$ should be rejected as pathologically insensitive to experience. For a discussion of such pathologies see Gupta 2006, ch. 4, and Gupta 2019, ch. 4. 
us to transition to ways of judging and acting toward others that respond, rather than to who they are, what they do, and why - to what pleasure or utility we seek to derive from them. As we make such transitions, we are likely to judge and act in ways that fail to do them justice. If conjoined with experience, a selfish view may thus make rational transitions to unjust beliefs, judgements, and actions.

Both of the above may apply to Sid. First, his selfishness may prevent him from seeing others justly, his appearances may be distorted; he doesn't care enough to look. Yet the transitions to the evaluative judgments and actions he offers in response to his experience may be completely rational, given his view. Second, even if his appearances are unaffected, his view may be so selfish that upon having experiences, he rationally transitions to judgments and actions that serve his needs, but fail to be responsive to who the people he interacts with are, to what they think, need, and intend as they act. Here is a third possibility: Sid's view may combine with strong dispositions to act selfishly, dispositions that prevent Sid from transitioning to actions that are rational in light of his view.

I return to the topic of dispositions below (in IV.2). For now, let us observe that in the first two cases, we will find fault with Sid. We will take his appearances to be selfishly distorted and his view overly egocentric. Even so, the judgments and actions Sid transitions to may still be perfectly rational, conditional on his experiences and his view. In the third scenario, however, Sid is not even conditionally rational. Instead of judging and acting in light with what is rational in light of his view and experience, selfish dispositions interfere. The anxious avaricious tentacles of the self (cf. Murdoch 1970, 103) may hide in various places. Of Sid, who here appears only as an illustrative caricature, we cannot say where they do. If we met him, we might find out, if we looked at and imagined him justly.

Note, parenthetically, that Sid himself may eventually have occasion to revise his view. For if his vision is indeed distorted and his actions indeed unjust, they will be unresponsive to reality and blind to the needs, hopes, intentions, and legitimate demands of others. This in turn will create the kind of friction mentioned in the last section. It may build up, thwart Sid's selfish plans, force him to revise his views, even compel him to look. Such revisions may of course make things worse, simply make Sid more shrewd, or, if more attentive to others, then just enough to serve his selfish aims better. But since this would not remove, only modify the friction, friction may still build up and eventually yield changes toward the less selfish. In our compassionate moods, we feel for those in whom such changes never occur, whose lives seem untouched by the light that (we imagine) guides us, and for whom friction never turns into the rock bottom of conversion. Of course, if changes do occur, they need not, typically will not, be as profound (let alone dramatic) as the conversion of Dickens' Scrooge or the redemption of Lucas' Darth Vader. Life is subtler than that kind of fiction and moral progress is slow, difficult, and piecemeal. Observers may not notice it (or may have long since stopped looking).

Returning to the good case, recall that unselfish, loving attention is geared at doing justice to who others are, involves imagining realistically what they believe, what options they can see, how they characterize these options, and how they differ from us. Such attention, if it springs from a suitable view, may make rational transitions to evaluations that are appropriate and fair, perhaps to actions that are directed at the common good. Doing this well is extremely difficult. Often, we fail. Moral progress, Murdoch would submit, requires humility and compassion. 'Humility' in this context translates into 'readiness to learn.' Others' perspectives may be blurred, too, yet clearer where ours are murky. If they disagree with us, we may benefit and learn from them by looking at and imagining them-unselfishly and justly. Compassion, on the other hand, arises from the realization that actions may look comparatively bad to us, yet good to others who evaluatively characterize them and the people they 
affect differently. Ideally, attending to others justly engenders understanding, which in turn facilitates attempts to help them improve, if, on closer inspection, their understanding seems deficient. This may fail and what looks like compassion (to us, too) can be self-serving paternalism in disguise. But attempts to help others may also be truly compassionate, empathetic responses to them, their outlooks, and their idiosyncratic features - actions that serve not selfish ends but the common good. In short: seeing others and imagining how things look to them realistically will make us reevaluate and recharacterize the options for action open to us and may make rational transitions to actions that are better not just for us, but for them also.

Above, we saw that presentationalists can handle cases that trouble both representationalists and relationalists: cases in which our views and concepts are muddled and cases in which background effects affect our view and experience. Self-conscious presentationalists must entertain the possibility that others understand and apply evaluative concepts differently and that subjects in identical environing circumstances may face different appearances. ${ }^{35}$ Moreover, they will acknowledge that different responses to identical circumstances can be equally rational, conditional on the responding subject's views. If so, however, presentationalists should embrace Murdoch's appeal to humility and compassion. Presentationalism entails that others may rationally transition to judgments and actions I disapprove of. When facing such judgments and actions, I should humbly consider that the other may have acted rationally. Perhaps my own view is deficient, my selfish ego may surreptitiously interfere with what I see and imagine, my appearances may be distorted. If I find that I disagree with others or their actions, this must not be an automatic reason for me to blame them (though reasons for blame may of course exist). Instead, disagreement with others may well motivate me to attend to them more closely, to learn more about how things really stand with them and the situation at hand, or to act compassionately, depending on what circumstances require or allow, and on what I can do. ${ }^{36}$

We thus arrive at Murdochian Presentationalism. There is much more to be explored than what I can here provide, but in nuce, I will say this: Murdochian presentationalism takes the theoretical insight of presentationalism - the realization that against the backdrop of differing views, different responses to identical circumstances can be equally (conditionally) rational-as motivating the Murdochian practical insight that acting well toward others requires that we transcend the constraints of our subjective rationality by opening ourselves up to being affected by our attempts to attend and imagine others and their actions justly. Support relations go both ways. Murdoch is a realist. For her, looking at others justly and freeing oneself from selfish fantasy are part and parcel not merely of the attempt to morally better oneself. They are also part of the quest for truth and understanding - the attempt to get better attuned to what is real. Indeed, moral progress aims for knowledge of the individual and once we accept the importance of just and unselfish attention in obtaining such knowledge, we should also accept that the practical pursuit of moral progress and the theoretical pursuit of rationality, truth, and knowledge of what else is real belong to one and the same project as two sides of one coin.

35 For presentationalists who keep a notion of content, further possibilities arise: another, B, could be appeared to in the same way as oneself, A, while B's appearances are associated with contents that differ from those associated with the same appearances for A; also, for B, both the appearances and the associated contents could differ from A's, etc.

36 Two remarks: 1) One can be mistaken about who one is and about what one is able to do. But if paying just attention is already difficult, it is even more difficult as something one engages in with respect to oneself (on this, both Aristotle 2014, IX.9, and Murdoch agree). 2) How far compassion toward those who act in ways that strike as us as cruel may go, and to what extent, if any, we are morally obliged to attend to them is a difficult question. 
The "quiet constant work of attention" (cf. Murdoch 1998, p. 200), Murdoch says, slowly builds up the world which we confront, see, and in which we can thus choose, "a world upon which our imagination has, at any given moment, already worked" (ibid. 199). Murdoch's suggestion here is that the options we take to be available for action, along with the people and things we see, are always and inevitably present to us in terms that are shaped by our idiosyncratic histories. As the presentationalist would say, they depend on the specifics of our view and the shape of the concepts it contains. Such histories will crucially involve prior occasions of attention, applications of (evaluative and other) concepts, interactions with others, and how our beliefs about how concepts relate to another have grown out of them. Such histories, the presentationalist would say, concern how our views have been shaped and revised through the continuous pressure of experience. Let us suppose that rather than merely looking (the neutral word), one can pay conscious attention (the good word) to others (see Murdoch 1970, 37). Let us assume, further, that such attention can be just. Finally, let us entertain, with Murdoch, that just attention is supportive of clear and realistic vision. Now, if presentationalism is ultimately geared at arriving at views that are subsequently more rational, more coherent, and more accurate, and if practical and theoretical pursuits are as closely related to one another as the discussion in the previous paragraph suggests, then engaging in increasingly just attention emerges as a habit that presentationalists should strive to cultivate-if only for instrumental reasons: it is broadly conducive to conceptual progress and potentially essential to the project of advancing their theoretical pursuits. ${ }^{37}$

According to presentationalism, we saw above, views (and the beliefs and concepts they comprise) develop, in part, ${ }^{38}$ under the pressure of experience, through subsequent applications of empirical concepts, e.g. in perceptual judgments, through which we may learn and enrich our view or realize that there is need for revision. Murdoch concurs. As our concepts develop, she claims, "a deepening process, at any rate an altering and complicating process, takes place" and "since we are human historical individuals the movement of understanding is onward into increasing privacy, in the direction of the ideal limit" (Murdoch 1970, 29). ${ }^{39}$ In making these remarks, Murdoch's focus is specifically on value concepts. However, she also hints at the possibility that such a process of complication and development toward an ideal limit could be one that all concepts undergo, even socalled ordinary empirical concepts such as color terms (ibid.). Presentationalists purport to provide a general account of how views can change under the pressure of experience. And if for views to change frequently entails that the beliefs and concepts they contain change along with them, we can see how presentationalists might flesh out the story of conceptual change toward an ideal limit that Murdoch hints at-not just regarding the ordinary empirical concepts and theories that presentationalists focus on, but regarding the evaluative concepts Murdoch focuses on as well.

This concludes my sketch of Murdochian presentationalism, which blends the language of presentationalism with Murdoch's language of just attention, clear vision, and unselfing. Presentationalism, I suggested, invites and serves to motivate the plea to treat others with humility and compassion that is implied in Murdoch's focus on just attention. I argued that Murdoch's account

37 To the extent that selfish dispositions are treated as separate from views, just attention should appear attractive as a method to reduce discrepancies between how, in light of their view, agents should act and how they in fact $d o$.

38 Changes in views, beliefs, and concepts can of course also be triggered by purely logical reflection.

39 Qua realist, Murdoch must take the ideal limit to be an accurate view on which agents who embark on their moral quest for truth from different starting points would eventually converge. The reference to privacy shows that to her, the development of views, concepts, and beliefs is a highly idiosyncratic affair. Whether Murdoch underestimates the role empirical debate about objects of joint attention can play with respect to expanding common conceptual ground regarding moral (and other) concepts is an interesting question. 
of just attention in turn complements the project of presentationalism, suggested, more generally, that theoretical and practical pursuits are inextricably intertwined, and proposed that presentationalism may help flesh out Murdoch's claims about how our moral (and other) concepts develop. Next, I will integrate two further pieces required to articulate the view I take to sustain P2: a clarification of what freedom is not and a broadly Kantian notion of individual autonomy.

\section{Freedom and Autonomy}

\section{IV.1 Freedom to vs. freedom from}

What is individual autonomy? The freedom, perhaps, to deliberately choose between publicly available options for action? To Murdochian presentationalists, this proposal must be doubly implausible. First, suppose I consider some action, $\varphi$. Assume, further, that $\varphi$ seems attractive to me, yet unfathomable to you. Perhaps we can overcome our differences. After talking and attending to you, you may adopt my characterization of $\varphi$-ing, or I may modify mine, based on what I can now see. ${ }^{40}$ Yet perhaps not. Resolving differences in how we understand concepts and how we apply them can be complicated, a life-long task. ${ }^{41}$ As we have come to understand already, paying just attention is difficult. Consequently, Murdochian presentationalists must hold that given (perhaps subtle) individual differences in view and, perhaps, appearances, options for action are typically not publicly available, not under the evaluative characterizations that matter to the agent. Some morally relevant actions may be available only to me. Reflecting with the aim of reevaluating others and their actions, for example, is a rather private affair. It involves replacing one idiosyncratically framed and understood evaluative characterization with another, updated one. Who, except me, could possibly engage in this activity? ${ }^{\text {42 }}$

Here is a second problem with the proposal: in moments of choice, Murdochian presentationalists will hold, most of the morally important work has already been done. Recall the following passage: "The world which we confront is a world upon which our imagination has, at any given moment, already worked. [...] we evaluate [...] largely, by the constant quiet work of attention and imagination" (Murdoch 1998, 199-200). To Murdochian presentationalists, what matters most morally are not isolated moments of choice. Instead, most important is the way in which we continuously attend and imagine others and the situations in which we find ourselves:

(2) [] $\mathrm{f}$ we consider what the work of attention is like, how continuously it goes on, and how imperceptibly it builds up structures of value round about us, we shall not be surprised

40 I might e.g. realize that $\varphi$-ing is unacceptable for me, too, as on my modified characterization, it conflicts with what else I deem good. I may not fully succeed in understanding your characterization-my attention is may be flawed or I may use the terms figuring in it differently. I may also disagree with you and still act the way you suggest. Were you to experience an untoward consequence of my acting this way_ one I anticipate, while you do not—you might learn from this more than by my repeatedly telling you. This is a standard tool in the parent's toolbox. I might also anticipate that acting as you suggest will make me experience an untoward consequence. If I care about your learning, I may be ready to face the untoward consequence and doing so may be an act of loving compassion. However, I might also just care about the expected pampering of my ego that I derive from my being able to tell you that $I$ told you so. As always, in interpersonal interactions, there is room for compassion and selfishness and what one's actions and their underlying motives are can be opaque not just to others, but also to oneself.

41 For an illustration of how such difficulties can arise not in moral contexts, but in the context of scientific classification, see the opening example in Hanson (1965 [1958]), ch. 1.

42 This is one of the things Murdoch's famous M\&D example brings out (see Murdoch 1970, 17ff., esp. 23). 
that at crucial moments of choice most of the business of choosing is already over. (Murdoch 1970, 37)

This is not to deny, of course, that choosing a path of action-especially under duress or time constraints - can require serious moral reflection, but to insist that such situations are no good models for moral activity in general. ${ }^{43}$ Moral activity is ongoing, and how we have come to characterize our options, through constant and quiet attention, often wears on its sleeves which one is best, so that we pursue it almost automatically.

(3) A mediocre man who achieves what he intends is not the ideal of a free man. To be free is something like this: to exist sanely without fear and to perceive what is real. I would be prepared to imply that one who perceives what is real will also act rightly. (Murdoch 1998, 201).

Selfish Sid, too, chooses. But as per passage (3), such choosing does not reveal his freedom. To Murdochian presentationalists, Sid's freedom must seem severely hampered. He cannot make out what his options really are. The good he aims to materialize is conceptualized in too narrow and selfish a fashion and lacking the discernment that just attention affords, the way he characterizes his options remains unrealistic and distorted. He transitions, even rationally, to judgments and actions which are based on bad vision and often unjust, which leads to friction and may leave his selfish plans at risk of being thwarted - though this need not be so, as we saw already.

To Murdochian presentationalist, freedom is not freedom to choose, but freedom from whatever distorts our views and blurs our vision - notably: selfishness and the fear that arises from entertaining the possibility that one might not obtain or keep what the ego desires. Freedom tethers us and our vision to reality, allows us to evaluate options clearly, and enables us to do what may in fact be good in a sense that transcends what may initially have seemed good to us. Let us next combine this view with a take on individual autonomy as resting, in part, on the capacity to bind oneself by norms.

\section{IV.2 Autonomy}

Being bound by norms — at least implicitly — is essential to intelligibly having views at all. Any view must be intelligible as a practice governed by various implicit—and, perhaps, explicit—norms that specify which inferential moves between concept applications, judgments, and actions are appropriate (or not). Within such a structure concepts acquire their specific shape and determinate (or determinable) content. ${ }^{44}$ As Murdochian presentationalists will insist, such a structure must also contain linkages that rationally link views, perceptual judgments and actions via possible experiences. ${ }^{45}$

43 As Murdoch puts it, what is required is a shift in imagery. She thinks that we should not understand moral activity primarily in terms of movement, in terms of discontinuous leaps of the isolated will, but in terms of the metaphor of vision that emerges from (and, we may add, is directed at) the continuous fabric of being (cf. Murdoch 1970, 22).

44 It is an interesting question, not to be pursued here, what the normative structure of a view must minimally be. Certainly, some minimal coherence constraint must be met. Arguably, norms must also hang together in a sufficiently dense way to confer conceptual content on the concepts whose conditions and consequences of application they govern. An account of the kinds of structures necessary for a practice to be discursive is provided in Brandom 2008.

45 This emphasis on experience sets apart Murdochian presentationalism from a view like e.g. Brandom's inferentialism that eschews the notion of experience entirely and tries to do just with the concept of reliably differentiated dispositions to respond to observable stimuli (see e.g. Brandom 1994; for criticism: McDowell 2010). 
Views so construed could be characterized in a number of ways. In principle, one way could be by specifying the norms that the agent should comply with, given what they believe. But this introduces complications, for even if we set aside pragmatic limitations, such a task raises the issue of competence. The bird's eye view from which what in fact follows from what can be seen must elude us: judgments concerning such issues cannot but happen against the backdrop of our own normative practice.

A different way of characterizing a view is by referring to rules that subjects who inhabit the practice sustaining it are de facto disposed to comply with. Many such rules will also be specified in normative terms. After all, an important part of the practice that sustains a view will be that of treating certain items (e.g. utterances and other actions) as correct (or not). Importantly, focusing on rules characterizing dispositions that inhabitants of a view de facto exhibit makes the characterization of a view more realistic. It lets in a set of factors that are especially pertinent to the topic at hand. For we may note that the rules characterizing de facto dispositions may well be at odds with the norms by which those who inhabit the view take themselves to be bound. After all, de facto dispositions will be shaped only in part by the respective inhabitant's explicit and implicit normative commitments. They will also reflect unconscious motives, drives, emotions, hopes, etc.-i.e. the complex psychological mechanism of those whose view is under consideration.

Clearly, rules that govern a subject's de facto dispositions need not, typically will not be explicitly available to those who comply with them. Some may be. ${ }^{46}$ Probably most, though, will govern the subject's judgments and actions implicitly, manifest, inter alia, in how they understand, relate, and apply moral and other notions and act. In a community, self-conscious clarity on such issues is likely to be distributed unevenly and is probably best increased not from some fictitious external point of view, but by processes of collective explication and negotiation.

Again, rules governing our de facto dispositions can and often will be co-determined by conscious and unconscious motives and may differ from the norms by which we think we are bound. In this context, it is natural to draw on a common interpretation of Kantian autonomy. According to it, autonomy is the capacity to impose a form of rational self-constraint: the capacity to deliberate and bind oneself by norms (moral, but also other ones). On this notion, selfish psychological factors that co-determine de facto rules but do not appear as either implicit or self-conscious commitments to norms introduce an element of heteronomy: to the extent that our actions and thoughts are determined by such factors, we are not autonomous. We can rephrase this in terms of Murdochian presentationalism: selfishness and fear may distort what we see, surreptitiously shape our view and how we characterize others and our options for action, and thus hamper our freedom. Improvement in individual autonomy then appears as an improvement of Murdochian freedom and, more generally, as a modification of how we exercise (and follow through on) our capacity to bind ourselves by normsone that minimizes selfishness both regarding what we bind ourselves by and as to whether we truly act on what we take our commitments to be, i.e. in line with what it is rational to transition to, given our view. Such improvement is naturally fostered by explication (though it is not the only way to foster it - modelling behavior is another). ${ }^{47}$

46 One might imagine a community of speakers in which no such norms are explicitly available as their language lacks the expressive power to explicate them. Brandom 1994 discusses a related possibility. For doubts, see McDowell 2005.

47 If, like Murdoch, we want to make room for the virtuous peasant, explication cannot be necessary for moral progress. Perhaps moral excellence can result from a naturally virtuous and unselfish disposition or from learning by intuitively imitating the virtuous. Lambert 2020 provides an interesting account of the potential importance that modelling appropriate behavior may take on in the public sphere, developed against the backdrop of Confucian ethics. 
Explicating norms by which we are-or take ourselves to be-bound and explicating heteronomous factors that co-determine how we are de facto disposed to act serves to increase our semantic, moral, and psychological self-consciousness. Here are three ways in which such explication can increase autonomy. First, some of the norms that shape our dispositions to act and think are socially transmitted and implicit in how we act. Explicating them makes them available for conscious endorsement. To transition from simply complying with an implicit norm-as it were passively and automatically_to willingly binding oneself by it is to move toward a more self-conscious and autonomous exercise of the appurtenant capacity. Second, and relatedly, explication makes implicit norms available for rejection and for individual or intersubjective refinement and negotiation-e.g. as one considers their applicability on occasions of (joint) attention. Third, explicating heteronomous factors increases self-awareness and can allow one to work towards changing one's dispositions in familiar ways. Consider the kind of self-awareness that enables you to stop yourself from getting upset about something that somebody says to you. Such self-awareness may e.g. involve the following realization: the utterance in question may not be directed at you, or not be meant the way you notice you are inclined to take it. You may even understand why you are so inclined. The utterance of your present interlocutor, B, may for instance remind you of what a past interlocutor, A, may have said to you - something that back then you may have found very hurtful. It is because you transfer what you take to be A's past adversarial intentions onto B that you incline toward a specific response. An increase in awareness and understanding can change our dispositions' manifestation conditions and, thus, the dispositions themselves. Awareness clarifies vision and enables us to counteract transference. It removes an illusion and increases our ability to attend to what is really there-in this case: $\mathrm{B}$, who differs from $\mathrm{A}$-and makes us more free.

Plausibly, many rules that characterize the dispositions we de facto comply with are largely due to our psychological and socio-cultural upbringing. Explicating them is a social task which requires reciprocal recognition, attribution of motives and reasons, and, where appropriate, criticism. What our norms ought to be, too, must be socially negotiated. In such activities, Murdochian presentationalists insist, just attention matters. It allows us to truly see others, to incorporate the valid points they may be raising, to issue just criticism, and to render compassionate assistance. And the smallest arena for such negotiations, one in which intimacy makes such negotiations particularly powerful, is that provided by romantic love.

The increasingly autonomous subject, then, consciously binds herself by decreasingly selfish norms, becomes more aware of and finds ways to excise ways in which heteronomous factors suffuse the fabric of her being, attends to others justly, recognizes them as trying to pursue the good they can see, and responds to them humbly and compassionately. To her, disagreement with others invites attention and provides opportunities for testing and refining the norms she embraces. She may welcome disagreement as potentially revelatory of subtle distortions of her own view, as an opportunity for detecting and overcoming residual selfishness, or as an opportunity for compassionate action geared toward assisting others in explicating and refining the norms that bind them, in turning them into norms they bind themselves by, and thus in increasing their individual autonomy. Full individual autonomy, so construed, is a distant ideal, one that we may not reach and that we may need to work towards together. With it in hand, we can finally return to P2.

\section{Just Love and the Ideal Lovers' Pledge}




\section{V.1 P2, Expanding Outlooks, and the Ideal Lovers' Pledge}

As per P2, recall, to be just, love must preserve or foster, not diminish individual autonomy. In light of the previous section (and inserting appropriate agentive terms) we can now gloss P2 as follows: a just lover must preserve or foster the beloved's individual autonomy. To do this is to preserve or foster the beloved's ability to self-consciously bind themselves by norms, to assist them in their endeavors to see and imagine others clearly, and, relatedly, to help them reduce the influence of heteronomous factors that may affect their views, distort their vision, and their dispositions to act.

According to Murdochian presentationalism, this is precisely what just lovers do. Whether it be preserving or fostering the beloved's autonomy, efforts geared toward these aims cannot succeed until the lover knows and understands the beloved well. We have seen that such knowledge, while difficult to obtain, is what just attention delivers. Seeing clearly who the beloved is and what options for action they see requires a certain amount of selflessness. To truly see their beloveds, a lover must acknowledge that their beloved, qua individual, is different from them. As lovers get to see and imagine their beloveds better, they get a sense of what they value, what vision of the good underlies and motivates their actions, and how heteronomous aspects may undermine their autonomy. Qua lover, lovers will wish their beloveds well. They will consider the vision of the good that they imagine their beloved aims for and try to appreciate its value (if it is not already obvious to them). They will support the beloved in their attempts to materialize that good, may strive to continuously explicate and negotiate individual and joint commitments, ${ }^{48}$ and gently and compassionately help the beloved explicate and excise heteronomous factors. They will also, and this matters, allow the beloved to reciprocate and in turn help the lover in corresponding ways. ${ }^{49}$

As lovers reevaluate their own options for action in light of what they see and what strikes them as good for both themselves and the beloved, there is a sense in which the lover's outlook expands and begins to incorporate the beloved's outlook - to the extent that they can see it. But doing this need not mean that all of the beloved's goals properly become one's own. There may well be projects my beloved pursues the point of which I fail to see. But I may decide to promote and support them anyway. For even if I cannot fully see their point, I may be able to see and appreciate that for my beloved, undertaking the commitment to pursuing such projects is an expression of their individual autonomy - something that matters to them deeply, is an important part of how they see themselves and of what they see themselves as moving toward. ${ }^{50}$ I need not want to move there or move there that way, but as a just lover, it will be essential for the pursuit of the vision of good that attracts me that my beloved be able to pursue theirs as well.

Just attention to the beloved may modify the range of the lover's options for action, but also, and crucially, what the lover perceives these options to be and entail. Just attention enables doing well by our beloved and, as I said above, transcends the lover's subjective rationality. One way in which this happens is that the characterizations of the lover's options for action get reframed by their knowledge of the beloved. Love expands, suffuses, and reorients the lover's outlook. Such reshaping need not always prioritize actions that the lover takes to be most rational, based on what they now see. Being

48 Again, explication, albeit a powerful tool to increase autonomy, may not be a necessary tool.

49 Providing unilateral assistance without accepting any in return may create dependence and be a way of surreptitiously inflating the assisting lover's ego.

50 For a very nuanced discussion of how to think about the distinction between sharing ends with the beloved and (unselfishly) sharing in the beloved's ends - a discussion that is also sensitive to the need to allocate the authority to decide how to pursue ends in ways that respect whose ends they primarily are - see Fahmy 2016. 
compassionate toward one's beloved may sometimes require that one refrain from pursuing what strikes one as the most rational option. Perhaps the beloved cannot imagine what merit one attributes to that option, would feel hurt were one to pursue it. Imaginatively anticipating the beloved's response to one's actions will both affect one's evaluative characterization of these options and may draw one toward responding to their otherness compassionately, i.e. in ways they can accept or ways that may help them see one's preferred option in a different light. But humility requires that one be open to the possibility that the beloved sees things better than one does-just love has room for faith and trust in the beloved and their vision, even against one's reason.

Here, then, is what I call the ideal lovers' pledge. As I see it, it is the undertaking of a commitment to try and justly attend and humbly and compassionately respond to one another, to acknowledge and respect one's differences, to mutually assist one another in explicating, clarifying, and developing one's views, joint and individual projects, to explicate the norms that characterize one's dispositions to act, to foster the beloved's autonomy by promoting their ends, helping them excise heteronomous factors, and letting them help one do the same. Taking this pledge, I contend, is itself an exercise of individual autonomy. It is a conscious, unselfish exercise of our capacity to bind ourselves by norms and involves a commitment to making continuous attempts to bind oneself by norms that are less selfish and thus, if acted upon, beneficial to both lovers (and, perhaps, to others more generally) ${ }^{51}$.

Since this commitment is fairly abstract, lovers will need to continually negotiate, in practice, how it ought to be understood and applied, always with a view to benefiting both lovers and making them more autonomous, by making their views and outlooks less selfish and better attuned to what is real. Such negotiations will typically rest on the mutual recognition of the lovers as capable of exercising their autonomy, and as being both able and entitled to hold each other accountable. At the same time, just lovers remain ever-ready to look again, to compassionately support each other when they fail, and to see their respective otherness as an opportunity to learn. Doing this well may well be an infinite task; injustice and heteronomy can enter in numerous and surreptitious ways. But preventing it from doing so by attending to and by responding to the beloved justly surely is worth striving for.

\section{V.2 Loving unions - shifting the imagery}

Throughout, I have argued for a position that makes it intelligible how to think of just love as preserving or maintaining individual autonomy. The view I promoted-Murdochian presentationalismis epistemologically motivated and interesting in various ways - not least in that, through its focus on attention and clear vision, it suggests that those pursuing theoretical ends need to take seriously moral and practical concerns to achieve their aims. It is productive, too, e.g. in that it allows fruitful communication between philosophy and psychology (as some of the examples bring out). If Murdochian presentationalism is false, it is false in interesting ways.

Just love, we saw, must be and remain sensitive to the fact that our beloved is different from us and that they may well remain partly unintelligible; we may forever fail to see exactly what they do or what they strive for. Put differently, the just lover should expect that although there may be convergence of outlooks, such convergence need not be total. But just lovers may rejoice in their

51 For an exploration of how Murdoch's notions of just attention may affect notions of freedom in the broader realm of the political—one that betrays in more than one way a shared interest and interpretative agreement with respect to some of the Murdochian topics discussed here, see Forsberg 2020. 
beloveds' otherness, not least because in engaging with and discovering it, they continue to find out more about their beloveds, but also about themselves.

In Helm 2017, Bennett Helm claims that for union theorists, a central task is that of spelling out just what the we of (ideal) loving unions comes to. In closing, let me briefly return to my qualms with the union view: I have no strong objection against them, but to the extent that union theorists think of loving unions in terms of a merger, I am unconvinced. For if Murdochian presentationalism is correct, the imagery of merging is misleading: in just love, neither identities nor ends merge-though ends may of course be shared and outlooks converge. ${ }^{52}$ A more helpful notion to characterize ideal loving relationships, I think, is the notion of harmony. In the tradition Murdochian presentationalism stands in, this is not a new suggestion. For example, one can find references to harmony in Weil's remarks on friendship: "Friendship," she says, "is a supernatural harmony, a union of opposites" (Weil 1977, 367). ${ }^{53}$ In fact, the tradition of conceptually linking love and harmony goes back much further. As Aditi Chaturvedi, commenting on the Empedoclean fragment B96, points out,

(4) harmonia stands for mixing in a particular proportion - there is balance and not complete unity or merging [...]. It entails a proper fitting together of discrete entities that nonetheless retain their original identity and don't simply blend into one another. (Chaturvedi 2016, 49) ${ }^{54}$

The notion of harmony-understood as a well-ordered and balanced fitting together of heterogeneous elements_provides an apt metaphor, I submit, a helpful image as we think about ideal loving relationships. In them, I argued, lovers retain and mutually foster their respective individuality - their harmonious relationship acknowledges the lovers' respective otherness. Such harmony is created and sustained by just love, which appreciates and supports the individuality, otherness, and individual autonomy of the lovers, aims at implementing a continuous commitment that I explicated in terms of the ideal lovers' pledge, and reorients the lovers by expanding their respective outlooks and reorienting them towards the good and the real.

\section{REFERENCES:}

Aristotle (2014). Nicomachean Ethics, translated with introduction and notes by C. D. C. Reeve. Indianapolis: Hackett.

Brandom, R. (1994). Making it Explicit. Reasoning, Representing, and Discursive Commitment. Cambridge (Mass.)/ London: Harvard University Press.

--- (2008). Between Saying and Doing: Toward an Analytic Pragmatism. Oxford: Oxford University Press.

Brewer, B. (2011). Perception \& its Objects. Oxford: Oxford University Press.

--- (2018). "Perceptual Experience and Empirical Reason," in: Analytic Philosophy 59 (1), 1-18.

--- (2019a). "Empirical reason: Questions for Gupta, McDowell, and Siegel," in: Philosophical Issues 29, 311323.

52 See Delaney 1996 and, again, Fahmy 2016, for why merging and sharing are very different.

53 The opposites Weil has in mind: on the one hand, our friend is something as necessary to us as food, on the other hand, they are someone whose autonomy and freedom, despite the affectionate bond of necessity that ties us to them, we are committed to preserve.

54 I have benefited from a serendipitous reading of this paper by Chaturvedi, my colleague at Ashoka, who also generously provided me with a very helpful manuscript on her interpretation of Empedoclean harmony (Chaturvedi $\mathrm{ms}$.). In it, she revises a remark that in the passage quoted in the text is omitted and in which she distinguishes harmony from love. In the manuscript, she argues, to my mind convincingly, that harmony, the appropriate fitting together of disparate entities, is precisely characteristic of Empledoclean Love (which, inter alia, is responsible for the creation of a harmonious, well-ordered cosmos). 
--- (2019b). "Empirical reason: Answers to Gupta, McDowell, and Siegel," in: Philosophical Issues 29, 366-377.

Broackes, J. (2012). "Introduction,” in: Broackes, J. (ed.). Iris Murdoch, Philosopher. A Collection of Essays. Oxford: Oxford University Press, 1-92.

--- (2019). "Iris Murdoch and Simone Weil". Talk at the Royal Institute of Philosophy, uploaded to YouTube on Jan 28, 2019. URL = https://www.youtube.com/watch?v $=$ LmCRWqkOiqs [last access: 06/30/2020].

Campbell, J. \& Q. Cassam (2014). Berkeley's Puzzle: what does experience teach us? Oxford: Oxford University Press.

Chaturvedi, A. (2016). "Harmonia and rta," in: Seaford, R. (ed.). Universe and Inner Self in Early Indian and Early Greek Thought. Edinburgh: Edinburgh University Press, 40-54.

--- (ms.). "Empedocleian Harmony."

Churchland, P. M. (1975). "Karl Popper's Philosophy of Science," in: Canadian Journal of Philosophy 5 (1), 145156.

Delaney, N. (1996). "Romantic Love and Loving Commitment: Articulating a Modern Ideal," in: American Philosophical Quarterly 33 (4, Oct. 1996), 339-356.

Engels Kroeker, E. (2019). "Reasons for Love," in: Martin, A. (2019), 277-287.

Fahmy, M. S. (2016). "Love's Reasons," in: Journal of Value Inquiry 50, 153-168. https://doi.org/10.1007/s10790-015-9504-y.

Fedock, R. (2020). "Dissolving the Illusion of the Love and Justice Dichotomy," in: this volume, pp.

Firestone, C. and B. Scholl (2016). "Cognition does not affect perception: Evaluating the evidence for "topdown' effects," in: Behavioral and Brain Sciences 39. https://doi.org/10.1017/s0140525x15000965

Fish, W. (2009). Perception, Illusion, and Hallucination. Oxford: Oxford University Press.

Forsberg, N. (2020). "The Freedom that Comes with Love," in: this volume, pp.

Genone, J. (2014). “Appearance and Illusion,” in: Mind 123 (490), 339-376.

--- (2016). "Recent Work on Naïve Realism," in: American Philosophical Quarterly 53 (1), 1-25.

Gupta, A. (2006). Empiricism and Experience. Oxford: Oxford University Press.

--- (2019). Conscious Experience. A Logical Inquiry. Cambridge (Mass.): Harvard University Press.

Hanson, N. R. (1965 [1958]). Patterns of Discovery. An Inquiry into the Conceptual Foundations of Science. Cambridge (Mass.): Cambridge University Press. [First published in 1958, edition cited: first paperback edition from 1965.]

Helm, B. (2017). "Love," entry in: Zalta, E. N. (ed.). The Stanford Encyclopedia of Philosophy (Fall 2017 Edition),

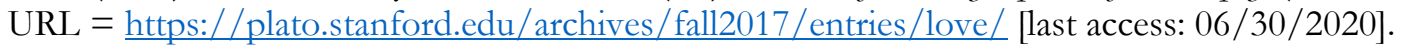

Hohwy, J. (2014). The Predictive Mind. Oxford: Oxford University Press.

Hopwood, M. (2018). “"The Extremely Difficult Realization That Something Other Than Oneself Is Real': Iris Murdoch on Love and Moral Agency," in: European Journal of Philosophy 26 (1), 477-501.

Hurka, T. (2017). "Love and Reason, The Many Relationship,” in: Engels Kroeker, E. \& L. Schaubroeck (eds.). Love, Reason, and Morality. London: Routledge, 1-19.

Jollimore, T. (2019). "Love, Romance, and Sex," in: Martin (2019), 61-71.

Kühler, Michael (2011). "Love as Union vs. Personal Autonomy," in: Farghaly, N. \& C. T. Toralba (eds.). Love on Trial: Adjusting and Assigning Relationships. Brill, 91-104. https://doi.org/10.1163/9781848880764010.

--- (2020). "Love as Union and Political Liberalism," in: this volume, pp.

Kvanvig, J. (2007). "Propositionalism and the Metaphysics of Experience," in: Philosophical Issues 17 (1), 165178.

Lambert (2020). "Love's Extension: Confucian familial love and the challenge of impartiality," in: this volume, pp.

Martin, A. (2015). “Love, Incorporated," in: Ethical Theory and Moral Practice 18 (4), 691-702.

--- (2019, ed.). The Routledge Handbook of Love in Philosophy. New York: Routledge.

McDowell, J. (2005). "Motivating Inferentialism. Comments on Making it Explicit (Ch. 2)," in: Pragmatics \& Cognition 13 (1), 121-140.

--- (2009). "The Given in Experience. Comment on Gupta," in: Philosopby and Phenomenological Research 79 (2), $468-474$.

--- (2010). “Brandom on Observation,” in: Weiss, B. \& J. Wanderer (eds.). Reading Brandom: On Making It Explicit. New York: Routledge, 129-144.

--- (2013). "Perceptual Experience: Both Relational and Contentful," in: European Journal of Philosophy 21, 144 157. 
--- (2019). "Responses to Brewer, Gupta, and Siegel," in: Philosophical Issues 29 (1), 390-402.

Murdoch, I. (1959). "The Sublime and the Good," in: The Chicago Review 13 (3, Autumn 1959), 42-55.

--- (1970). The Sovereignty of Good. London: Routledge \& Kegan Paul.

--- (1998). Existentialists and Mystics: Writings on Philosophy and Literature, edited and with a preface by P. Conradi, foreword by G. Steiner. New York: Allen Lane The Penguin Press.

Nanay, B. (2014). "The Representationalism versus Relationalism Debate: Explanatory Contextualism about Perception,” in: European Journal of Philosophy. https://doi.org/10.1111/ejop.12085

Nozick, R. (1989). “Love's Bond,“ in: Nozick, R. The Examined Life: Philosophical Meditations. New York: Simon \& Schuster, 68-86.

Rödl, S. (2007). Self-Consciousness. Cambridge (Mass.): Harvard University Press.

Rosenhagen, R. (2018). Experience and Belief: An Inquiry Into the Doxastic Variability of Experience. Doctoral Dissertation, University of Pittsburgh. [URL: http://d-scholarship.pitt.edu/id/eprint/35163]

--- (2019a). "Toward Virtue: Moral Progress through Love, Just Attention, and Friendship," in: Dalferth, I. \& T. Kimball (eds.). Love and Justice. Consonance or Dissonance (=Religion in Philosophy and Theology, Book 101). Tübingen: Mohr Siebeck, 217-240.

--- (2019b). “Norwood Russell Hanson's account of experience: an untimely defense," in: Synthese (2019). https://doi.org/10.1007/s11229-019-02395-3.

--- (ms). "Reformed Empiricism, Rational Linkages, and Rational Contribution". Talk presented on February 15, 2020, at the Reformed Empiricism and its Prospects conference at the IIC in New Delhi, India.

Schaffer, J. (2009). "On What Grounds What," in: Manley, D., D. J. Chalmers, \& R. Wasserman (eds.): Metametaphysics: New Essays on the Foundations of Ontology. Oxford: Oxford University Press, 347-383.

Schellenberg, S. (2014). "The Relational and Representational Character of Perceptual Experience," in: Brogaard, B. (ed.) (2014). Does Perception Have Content? Oxford: Oxford University Press, 199-219.

--- (2018). The Unity of Perception. Oxford: Oxford University Press.

Sellars, W. (1963). "Philosophy and the Scientific Image of Man," reprinted in: Sellars, W. Science, Perception and Reality. London: Routledge \& Kegan Paul Ltd, and New York: The Humanities Press, 1-40.

Siegel, S. (2017). The Rationality of Perception. Oxford: Oxford University Press.

Singer, I. (2009). Philosophy of Love: A Partial Summing-up. Cambridge (Mass.): MIT Press.

Soble, A. (1997). "Union, Autonomy, and Concern," in: Lamb, R. E. (ed.). Love Analyzed. Westview Press, 6592.

Weil, S. (1977). The Simone Weil Reader, edited by G. A. Panichas. Wakefield, Rode Island/London: Moyer Bell. 